\title{
Outcome of Acute Renal Failure Associated with Cardiac Surgery in Infants
}

\author{
João Egídio Romão Jr, Miguel G. Fuzissima, Armando F. Vidonho Jr, Irene L. Noronha, \\ Paulo Sérgio L. Q uintaes, Hugo Abensur, Maria Regina T. A raújo, Ivanir Freitas J r, Marcello Marcondes
}

São Paulo, SP - Brazil

Objective - To analyze the impact of acute renal failure $(A R F)$ on the evolution of infants undergoing cardiac surgery.

Methods - We assessed 15 infants undergoing cardiac surgery who developed (ARF). Their demographic, clinical and surgical data, and evolution were analyzed.

Results - Their mean age was 4.4 4.0 months (8 days to 24 months). Twelve infants were males, and 4 patients already had ARF at surgery. The primary cause of ARF was immediate acute cardiac dysfunction in 10 infants, cardiac dysfunction associated with sepsis in 2 infants, and isolated sepsis in 3 infants. All children depended on mechanical ventilation during their postoperative period, 14 infants used vasoactive drugs, and 11 had an infectious process associated with ARF. Thirteen infants required dialytic treatment. Eleven infants developed oluguric ARF, and all had to undergo peritoneal dialysis; of the 4 patients with non-oliguric, 2 required dialysis, the main indication being hypervolemia. Of these 13 dialyzed infants, 4 died in the first 24 hours because of the severity of the underlying cardiac disease (mean urea level of $49 \pm 20 \mathrm{mg} / \mathrm{dl}$ ). The mortality rate for the entire group was $60 \%$, and it was higher among the patients with oliguria ARF (73\% vs 25\%, $p<0.001)$. The cause of death was acute cardiac dysfunction in 6 infants (early type-1ARF) and sepsis in the 3 remaining infants (late type-2ARF).

Conclusion - The mortality rate of ARF associated with cardiac surgery in infants was hight, being higher among children with oliguria; peritoneal dialysis was indicated due to clinically uncontrolled hypervolemia and not to the uremic hypercatabolic state

Key words - acute renal failure, cardiac surgery, infants, peritoneal dialysis

Real e Benemérita Beneficência Portuguesa de São Paulo

Mailing address: João Egídio Romão Jr - Rua Maestro Cardim, 560/171 - 01322030 - São Paulo, SP, Brazil

English version by Stela Maris C. e Gandour
Acute renal failure is a complication diagnosed in patients undergoing cardiac surgery. It occurs in up to $9 \%$ of the children undergoing this type of intervention ${ }^{1-7}$. In most cases, acute renal failure is accompanied by either oliguria or anuria and is related to low output failure. Even though acute renal failure may reverse spontaneously in the first 48 hours after surgery, it frequently results in hypervolemia and severe electrolyte disorders that may cause significant morbidity and even occasional mortality.

The treatment for acute renal failure includes, in addition to severe fluid restriction and use of diuretics, removal of fluids through dialysis or hemofiltration, or both ${ }^{5-7}$. Recent evidence suggests that active fluid removal in patients with acute renal failure and low cardiac output after cardiopulmonary surgery may improve hemodynamic variables ${ }^{8,9}$. Several studies have emphasized, mainly in the last few years, the use of extracorporeal therapeutics to treat these children $^{8-12}$. In our service, however, children with acute renal failure following cardiac surgery are routinely treated with intermittent or continuous peritoneal dialysis, which is an effective and safe method that requires no advanced technology.

The objective of the present study was to review our experience with infants with acute renal failure following heart surgery over the last few years, emphasizing the outcome of these infants.

\section{Methods}

We retrospectively analyzed the medical reports of all 15 infants (age <24 months) with acute renal failure associated with heart surgery followed up in the Nephrology Clinic of the Hospital da Beneficência Portuguesa de São Paulo, from January ' 95 to December' 96 . All infants stayed in the intensive care unit under the management of a team of specialists in pediatric cardiac surgery. Table I shows the clinical data of these infants. We observed demographic data of the patients, characteristics of the heart disease and surgery, factors that could be important for the pathogenesis of 


\begin{tabular}{|c|c|c|c|c|c|c|c|}
\hline \multicolumn{8}{|c|}{ Table I - Clinical data of the patients studied } \\
\hline $\mathrm{N}$ & Age & Diagnosis & $\begin{array}{c}\text { Day of the } \\
1^{\text {a }} \mathrm{PD}\end{array}$ & $\begin{array}{l}\text { Duration } \\
\text { of the PD }\end{array}$ & $\begin{array}{c}\text { preU } \\
(\mathrm{mg} / \mathrm{dl})\end{array}$ & $\begin{array}{c}\text { Udur } \\
(\mathrm{mg} / \mathrm{dl})\end{array}$ & outcome \\
\hline & 1 & $3 \mathrm{~m}$ & $\mathrm{VSD}+\mathrm{PS}$ & $1^{\text {st }} \mathrm{PO \#}$ & $0.5 \mathrm{~d} *$ & 15 & Death \\
\hline 2 & $23 \mathrm{~d}$ & $\mathrm{PDA}+\mathrm{ADPT}$ & $1^{\text {st }} \mathrm{PO}$ & $4 \mathrm{~d}$ & 71 & 46 & Discharge \\
\hline 3 & $3 \mathrm{~m}$ & Tetr. of Fallot & $4^{\text {th }} \mathrm{PO}$ & $0.5 \mathrm{~d} *$ & 59 & & Death \\
\hline 4 & $3 \mathrm{~m}$ & PDA & $11^{\text {th }} \mathrm{PO}$ & $0.5 \mathrm{~d} *$ & 62 & & Death \\
\hline 5 & $8 \mathrm{~d}$ & $\begin{array}{c}\text { LVH+PDA+ } \\
\text { ASD+VSD }\end{array}$ & $1^{\text {st }} \mathrm{PO}$ & $0.5 \mathrm{~d} *$ & 63 & 26 & Death \\
\hline 6 & $29 \mathrm{~d}$ & $\mathrm{PDA}+\mathrm{ADPT}$ & $2^{\text {nd }} \mathrm{PO \#}$ & $4 \mathrm{~d}$ & 29 & 23 & Discharge \\
\hline 7 & $9 \mathrm{~m}$ & $\mathrm{ASD}+\mathrm{AoS}+\mathrm{PS}$ & $2^{\text {nd }} P O$ & $24 \mathrm{~d}$ & 81 & 57 & Death \\
\hline 8 & $2 \mathrm{~m}$ & PS & $1^{\text {st }} \mathrm{PO \#}$ & $10 \mathrm{~d}$ & 83 & 56 & Death \\
\hline 9 & $4 \mathrm{~m}$ & VSD & $1^{\text {st }} \mathrm{PO}$ & $33 \mathrm{~d}$ & 98 & 68 & Discharge \\
\hline 10 & $18 \mathrm{~d}$ & $\mathrm{LVH}+\mathrm{PA}+\mathrm{TA}$ & $16^{\text {th }} \mathrm{PO}$ & $2 \mathrm{~d}$ & 126 & 96 & Death \\
\hline 11 & $24 \mathrm{~m}$ & ASD+ADPT & $5^{\text {th }} \mathrm{PO}$ & $* *$ & 136 & & Discharge \\
\hline 12 & $5 \mathrm{~m}$ & $\mathrm{AoC}+\mathrm{VSD}+\mathrm{ADPT}+\mathrm{AoS}$ & $8^{\text {th }} \mathrm{PO}$ & $12 \mathrm{~d}$ & 93 & 82 & Death \\
\hline 13 & $10 \mathrm{~m}$ & PDA & $2^{\text {nd }} \mathrm{PO}$ & $5 \mathrm{~d}$ & 150 & 132 & Death \\
\hline 14 & $1 \mathrm{~m}$ & $\mathrm{ASD}+\mathrm{AoC}+\mathrm{PDA}$ & $2^{\text {nd }} \mathrm{PO}$ & $* *$ & 144 & & Discharge \\
\hline 15 & $19 \mathrm{~d}$ & $\mathrm{LVH}+\mathrm{PDA}+\mathrm{ASD}$ & $2^{\text {nd }} P O \#$ & $3 \mathrm{~d}$ & 93 & 81 & Discharge \\
\hline $\begin{array}{l}\text { PD } \\
\text { defe } \\
\mathrm{AD} \\
\text { dial }\end{array}$ & eal dia & $\begin{array}{l}\text { PreU- serum urea prior to dia } \\
\text { stenosis; AoS- aortic stenosis } \\
\text { age of the pulmonary trunk; } \mathrm{P} \\
\text { required; \# ARF prior to surg }\end{array}$ & $\begin{array}{l}\text { Udur- mean } \\
\text { I- left ventric } \\
\text { ersistence of }\end{array}$ & $\begin{array}{l}\text { uring perito } \\
\text { sia; PA- pul } \\
\text { sus; PO- po }\end{array}$ & $\begin{array}{l}\text { VSD- ve } \\
\text { ia; TA- t } \\
\text { eriod; } * d\end{array}$ & $\begin{array}{l}\text { tal defect } \\
\text { sia; AoC } \\
\text { he first } 2\end{array}$ & $\begin{array}{l}\text { - atrial septa } \\
\text { ic coarctation } \\
\text { s of peritone }\end{array}$ \\
\hline
\end{tabular}

acute renal failure, use of vasoactive drugs, and mainly the evolution after the diagnosis of acute renal failure with the clinical management adopted.

Acute renal failure was diagnosed when serum levels of creatinine increased $30 \%$ above basal values, a reduction in diuresis was observed in the absence of apparent hypovolemia, and a clinical trigger was evident.

The indication for dialysis included one or more of the following conditions: anuria or oliguria $(<0.5 \mathrm{~mL} / \mathrm{kg} /$ hour $)$ for 12 hours or more; hyper-hydration or hypervolemia, or both nonresponsive to hydric restriction and use of diuretics (furosemide, $1-2 \mathrm{mg} / \mathrm{kg} /$ intravenous dose); hyperkalemia (serum potassium $>5.0 \mathrm{mEq} / \mathrm{L}$ ); and the need to infuse fluids (for parenteral nutrition, for example) in the presence of diminished renal function and a markedly positive hydric balance. Infants requiring extrarenal clearance underwent peritoneal dialysis according to an already described technique ${ }^{13}$ and pediatric peritoneal catheters were installed by percutaneous (rigid catheters) or surgical (flexible catheters) via. Sessions were performed according to the manual technique with installation of a graduated buret in the infusion system of smaller infants and using 30 to $50 \mathrm{~mL} / \mathrm{kg}$ of a commercially available dialytic solution (glucose concentration of $1.5 \%$ and $4.25 \%$ ) at each change. Initially, changes in the bath occurred every hour in the first 24 to 36 hours; with stabilization of the biochemical findings (control of the hyperkalemia, of the metabolic acidosis, and of uremia) and control of the hyper-hydration of the infant, the interval between the changes was increased to 2 to 4 hours (some patients were kept in continuous peritoneal dialysis for up to 33 days).

Quantitative data are presented as mean \pm standard deviation. Differences between qualitative data were analyzed with the Fisher exact test with $p<0.05$ considered as significant, and the statistical package InStat (GraphPad Software Inc, San Diego, EUA) was used.

\section{Results}

The mean age of the infants studied was $4.4 \pm 4.0$ months, ranging from eight days to 24 months. Twelve (80\%) infants were males. Eleven (73\%) patients developed acute renal failure following cardiac surgery, and 4 (27\%) patients already had acute renal failure prior to the surgical procedure (increasing serum creatinine levels $>30 \%$ of the basal value). No patient underwent dialysis or ultrafiltration during the surgical procedure. Table I shows clinical data of the patients.

The cause of acute renal failure was immediate acute cardiac dysfunction (low cardiac output and cardiogenic shock) in 10 infants, cardiac dysfunction associated with sepsis in 2 patients, and septic shock in 3 infants. Fourteen (93.3\%) patients used vasoactive drugs, and 11 (73\%) had an infectious process associated with acute renal failure. Eleven infants had renal failure with concomitant oliguria (diuresis $<1 \mathrm{~mL} / \mathrm{kg} / \mathrm{hour}$ ), and all infants had to undergo dialysis; of the 4 other infants who evolved with acute renal failure without concomitant oliguria, half required dialysis, the main indication being the presence of hypervolemia, pulmonary congestion, and congestive heart failure.

In the 13 (87\%) infants requiring dialysis, peritoneal dialysis with a flexible catheter was the most used method (73\% of the infants). The indication for dialysis was hypervolemia in 15 patients (associated with uremia in 5 infants), in the presence of reduced diuresis and the necessity to use fluid infusion. Dialysis was instituted between the first and the $16^{\text {th }}$ postoperative days (median $=$ the $2^{\text {nd }} d a y$ ). In this group of infants, the mean levels of urea and creatinine at the moment of indication of the treatment were $85.7 \pm 44.4 \mathrm{mg} /$ $\mathrm{dL}$ and $2.2 \pm 1.9 \mathrm{mg} / \mathrm{dL}$, respectively. Of these infants, 4 died in the first hours of the treatment, not because of acute renal failure but due to the severe underlying disease; their mean 
serum urea level at the beginning of dialysis was $49 \pm 20 \mathrm{mg} /$ $\mathrm{dL}$. The other 9 patients had at the beginning of the dialysis a mean serum urea level of $86 \pm 44 \mathrm{mg} / \mathrm{dL}$. With dialysis, metabolic acidosis, hyperkalemia, and hypervolemia could be controlled in all infants in the first 12 to 24 hours of treatment, and the mean serum level of urea was $75.7 \pm 33 \mathrm{mg} / \mathrm{dL}$ during the period when dialysis was maintained (up to the last session of peritoneal dialysis or death). This showed the efficacy of the extrarenal clearance procedure used. The mean duration of dialysis was $6.8 \pm 10.5$ days (median $=4$ days), ranging from one-half day to 33 days; in seven infants, the duration of continuous peritoneal dialysis ranged from 4 to 33 days (mean $=13.1 \pm 11.2$ days ) and, in the remaining, intermittent peritoneal dialysis was maintained for 12 to 48 hours. No infant had peritonitis or any major complication during the treatment, except one infant with perforation of the urinary bladder caused by the rigid catheter, which was corrected with repositioning of the catheter.

We observed a mortality rate of $60 \%$ ( 9 deaths), which was higher among the oliguric patients $(73 \%)$ than among the nonoliguric $(25 \%)$ patients. Of the 12 infants developing acute renal failure due to acute cardiac dysfunction in the first 5 days after surgery (type- 1 acute renal failure), half died due to heart failure and cardiogenic shock. All infants developing acute renal failure due to a systemic infectious process after the $7^{\text {th }}$ postoperative day (type- 2 acute renal failure) died because of sepsis and septic shock.

\section{Discussion}

The early postoperative period of heart surgery for cardiac malformations in infants may be associated with systemic circulatory failure and, consequently, with acute renal failure. The incidence of acute renal failure in these infants has been reported in up to $9 \%^{1,4-8}$, and this association has been related to high morbidity and mortality. Acute renal failure in these patients usually has a multifactorial character $^{2,4}$, and its more frequent manifestations are as follows: acute cardiac failure, reduction in diuresis, elevation in the serum levels of urea and creatinine, and a very positive hydric balance. When clinical and drug management cannot reverse these manifestations, dialysis is mandatory. In this situation, dialysis in children with acute renal failure is required until the abnormalities are corrected, the cardiac function improves, and the kidneys recover their normal function, which happens a few days later. The objective in most patients is to interrupt the cycle of hydric retention, cardiac overload, and tissular edema (mainly pulmonary edema), which if not rapidly controlled may contribute to death. In several studies ${ }^{1-6,14}$, the frequency of dialysis ranged from $1.6 \%$ to $7.7 \%$ of the patients undergoing cardiotomy.

The use of peritoneal dialysis in children with acute renal failure following cardiac surgery has proved to be an effective and safe method of easy installation, requiring no special infrastructure and no specially or complexly trained staff (nothing different from that already existing in any intensive care unit) ${ }^{1,2,4,6,14,15}$. The use of rigid catheters resultad in a good evolution in our patients maintained in peritoneal dialysis for a short-term period. On the other hand, their use for long periods (continuous peritoneal dialysis) was associated with a higher incidence of peritonitis ${ }^{13,16,17}$. Therefore, in the majority of the patients we advise the surgical insertion of a flexible peritoneal catheter (Tenckhoff catheter) under direct visualization. This installation may even take place during cardiac surgery ${ }^{18}$, and the catheter may be used for several days with total safety ${ }^{13}$. For those catheters surgically placed, we observed no significant hemorrhages, infection at the site of catheter insertion, or troublesome leaking, even though problems of obstruction or drainage requiring catheter replacement have been described in the literature. Kholi et al ${ }^{19}$ and Hanson et al ${ }^{20}$ showed only one and two cases, respectively, of catheter malfunctioning. They also had no mechanical complications in the children studied ( 31 and 22 children, respectively). Lattout et $\mathrm{al}^{21}$ and Reznik et $\mathrm{al}^{22}$ reported complications in catheter functioning in around $30 \%$ of the catheters inserted in their pediatric patients.

Several authors have reported that peritoneal dialysis may not be effective in removing fluids or nitrogen debris in hypercatabolic patients and also that the competence of the peritoneal membrane may be impaired in patients in shock ${ }^{10}$. These facts may be challenged either by clinical demonstration of this or by other studies ${ }^{1,2,4,6,14}$, or by data showing that in patients in shock peritoneal blood perfusion is not reduced enough to impair the efficacy of dialysis ${ }^{23}$.

The simplicity of peritoneal dialysis is in contrast to the complexity of the techniques of extracorporeal clearance in children, which require highly specialized and trained personnel and the use of specific and expensive material and equipment. In addition, children have a proportionally larger peritoneal surface than adults do (peritoneal surface of children per unit of weight is twice that of adults) ${ }^{24}$. Therefore, peritoneal dialysis in children has half the efficacy when compared with hemodialysis; in adults, however, this difference is $20 \%{ }^{25}$. Considering the evolution of children with acute renal failure and cardiac surgery, several studies have reported the use of extracorporeal dialysis [continuous arteriovenous hemofiltration $(\mathrm{CAVH})$ and continuous venovenous hemofiltration $(\mathrm{CVVH})]^{8,9,11,12}$. All these studies have shown a high mortality rate, but early and aggressive use of extracorporeal dialysis has been related to a less lethal prognosis, like that reported for peritoneal dialysis ${ }^{12}$.

The mortality rate in children with acute renal failure following heart surgery has been reported ranging from $10 \%$ to $90 \%{ }^{1-6,10,12,20}$, and our data confirm these values. This prognosis has been most determined by the underlying disease, intercurrent infections, and hemodynamic changes than by the dialytic method employed. Former studies reported mortality above $70 \%$ in children undergoing heart surgery and requiring dialysis, showing that dialysis could not benefit the evolution of these patients. This has resulted in a certain reluctance to indicate and start dialysis ${ }^{10}$. More recent studies have reported much lower mortality rates (even 
below 50\%) in children undergoing dialysis soon after surgery and in a more intense manner ${ }^{26-28}$. The notion of early dialysis is corroborated by data showing that dialysis enhances renal perfusion and decreases hydric overload, mainly in patients with right heart failure, in whom a peritoneal catheter was installed during surgery ${ }^{26}$. In the presence of oliguria resistant to diuretics in the early postoperative period, the peritoneal dialysis system should be installed immediately. It is worth emphasizing that even in infants with clinical acute renal failure, the mortality rate has been reported as high, reaching values around $35 \%-40 \%{ }^{29}$.

Finally, we would like to stress that acute renal failure related to heart surgery in children, like that reported in adults, has two well-defined characteristics as follows: a) type 1 acute renal failure - the acute renal failure occurs in the
Acute renal failure associated with cardiac surgery in infants

early postoperative period, within the first 5 days following the primary surgical procedure, and is secondary to acute heart failure, the cardiogenic shock being the major factor for the patient's death; b) type 2 acute renal failure - the acute renal failure occurs after the $7^{\text {th }}$ day of the postoperative period, is secondary to severe infections, and sepsis is the major cause of death in these children ${ }^{30,31}$.

In conclusion, acute renal failure in infants undergoing heart surgery is a critical situation in which most patients require dialysis. In our study, all patients underwent peritoneal dialysis, mainly because of clinically uncontrolled hypervolemia and not because of the uremic hypercatabolic status. Even though peritoneal dialysis was effective and begun early, the mortality rate was high $(60 \%)$ and was related to the severe hemodynamic disorder present aggravated by acute renal failure.

\section{References}

1. Baxter P, Rigby M, Jones O, Lincoln C, Shinebourne E. Acute renal failure following cardiopulmonary bypass in children: results of treatment. Int J Cardiol 1985; $7: 235-9$.

2. Rigden S, Barratt T, Dillon M, de Leval M, Stark J. Acute renal failure complicating cardiopulmonary bypass surgery. Arch Dis Child 1982; 57: 425-30.

3. Yeboah ED, Petrie A, Pead JL. Acute renal failure and open heart surgery. Br Med J 1972; 1: 415-8.

4. Chesney RW,Kaplan BS, FreedomRM,HallerJA, Drummond KN. Acuterenal failure: an important complication of cardiac surgery in infants. J Pediatr 1975; 87: 381-8.

5. John EG, Levitsky S, Hastreiter AR. Management of acute renal failure complicating cardiac surgery in infants and children. Crit Care Med 1980; 8: 562-9.

6. Gomez-Campdera FJ, Maroto-Alvaro E, Galinanes M, GarciaE, Duarte J, RengelAranda M. Acute renal failure associated with cardiac surgery. Child Nephrol Urol 1988; 9: 138-43.

7. Shaw NJ, Brocklebank JT, Dickinson DF, Wilson N, Walker DR. Long-term outcome for children with acute renal failure following cardiac surgery. Int J Cardiol 1991; 31: 161-5.

8. Coraim F, Coraim H, Ebermann R, Stellwag F. Acute respiratory failure after cardiac surgery: clinical experience with the application of continuous arteriovenous hemofiltration. Crit Care Med 1986; 14: 714-8.

9. Zobel G, Stein J, Kuttnig M, Beitzke A, Metzler H, Rigler B. Continuous extracorporeal fluid removal in children with low cardiac output after cardiac operations. J Thorac Cardiovasc Surg 1991; 101: 593-7.

10. Fleming F, Bohn D, Edwards H, Cox P, Geary D, McCrindle BW, Williams WG. Renal replacement therapy after repairs of congenital heart disease in children. J Thorac Cardiovasc Surg 1995; 109: 322-31.

11. Leyh RG, Notzold A, Kraatz EG, Sievers HH, Bernhard A. Continuous venovenous haemofiltration in neonates with renal insufficiency resulting from low cardiac output syndrome after cardiac surgery. Cardiovasc Surg 1996; 4: 520-5.

12. Paret G, Cohen AJ, Bohn DJ, Edwards H, Taylor R, Geary D, Williams WG. Continuous arteriovenous hemofiltration after cardiac operations in infants and children. J Throrac Cardiovasc Surg 1992; 104: 1225-30.

13. Romão JrJE. Métodos dialíticos. In:HirschheimerMR, Matsumoto T, CarvalhoWB Terapia Intensiva Pediátrica, Atheneu Editora, Rio de Janeiro, 1989; pp. 477-98.

14. Werner HÁ, Wensley DF, Lirenman DS, LeBlanc JG. Peritoneal dialysis in children after cardiopulmonary bypass. J Thorac Cardiovasc Surg 1997; 113: 64-70.

15. Malheiro PS, Burdman EA, Abdulkader RC, Daher E, Abensur H, Sabbaga E, Marcondes M. Peritoneal dialysis in low-weight children with congenital heart disease. Renal Fail 1989, 11: 67.
16. Alexander SR. Peritoneal dialysis in children. In Peritoneal Dialysis (Nolph KD, ed.), $3^{\text {rd }}$ ed. Netherlands: Kluwer 1989, pp. 343-64.

17. Day RE, White HR. Peritoneal dialysis in children. Review of 8 years experience Arch Dis Child 1977; 52: 56-61.

18. Sano S, Takagaki N, Koumoto T, Arai S, Nakanishi H, Sugawara E, Komoto Y, Teramoto S. Perioperative insertion of peritoneal dialysis catheter. Kyobu Geka 1993; 46: 580-1.

19. Kholi HS, Arora P, Kher V, Gupta A, Sharma RK, Bhaumik SK. Daily peritoneal dialysis using a surgically placed Tenckhoff catheter for acute renal failure in children. Renal Fail 199; 17: 51-6, 5

20. Hanson J, Loftness S, Clark D, Campbell D. Peritoneal dialysis following open heart surgery in children. Pediat Cardiol 1989; 10: 125-8.

21. Lattout OM, Rickets RR. Peritoneal dialysis in infants and children. Am Surg 2: 66-9, 1986.

22. Reznik VM, Griswold WR, Peterson BM, Rodarte A, Fervis ME. Peritoneal dialysis for acute renal failure in children. Paediatr Nephrol 1991; 5: 715-7.

23. Nolph KD, popovich RP, Ghods AJ, Twardowski Z. Determinants of low clearance of small solutes during peritoneal dialysis. Kidney Int 1978; 13: 117-21.

24. Kohaute E. Peritoneal dialysis in pediatric patients. In: Nissenson AR, Fine RN, Gentile DE (eds.). Clinical Dialysis, Appleton Cnetury Croft, Conn., EAU, 1994, pg 647-60.

25. Esperanca MJ, Colina DL. Peritoneal dialysis efficiency in relation to body weight. J Pediatr Surg 1966; 1: 162-9.

26. Book K, Ohqvist G, Bjork VO, Lundberg S, Settergren G. Peritoneal dialysis in infants and children after open heart surgery. Scand J Thorac Cardiovasc Surg 1982; 16: 229-33.

27. Zobel G, Stein JI, Kuttnig M, Beitzke A, Metzler H, Rigler B. Continuous extracorporeal fluid removal in children with low cardiac output after cardiac operations. J Thorac Cardiovasc Surg 1991; 101: 593-7.

28. Mee RBB. Dialysis after cardiopulmonary bypass in neonates and infants. J Thorac Cardiovasc Surg 1992; 103: 1021-2.

29. Blowey DL,McFarland K, AlonU,McGrow-Houchens M,Hellerstein S, Warady BA Peritoneal dialysis in the neonatal period; outcome data. J Perinatol 1993; 13: 59-64.

30. Tavares RS, Vidonho Jr AF, Noronha IL, Quintaes PSL, Abensur H, Araújo MRT, Freitas Jr I, Marcondes MM, Romão Jr JE. Insuficiência renal aguda em pacientes submetidos a cirurgia cardíaca: Impacto da época de sua apresentação (abs.). J Bras Nefrol 1997; 19: 87.

31. Bellomo R, Ronco C. The kidney in heart failure. Kidney Int 1998; 53 (supl.66) S58-61. 